\section{Carmen Ruiz Barrionuevo}

Catedrática de Literatura Hispanoamericana en la Universidad de Salamanca, es Directora de la Cátedra de Literatura Venezolana «José Antonio Ramos Sucre» en la misma Universidad. Ha trabajado, sobre todo, autores cubanos y venezolanos del siglo $\mathrm{XX}$, así como poesía del mismo siglo desde el modernismo. Entre sus publicaciones $E l$ "Paradiso» de Lezama Lima, Madrid, Ínsula, 1980; La mitificación poética de Julio Herrera y Reissig, Salamanca, Universidad, 1991; Gonzalo Rojas, Cinco visiones, Eds. de la Universidad de Salamanca, 1992; con César Real Ramos: José Martí, En un domingo de mucha luz. Cultura, historia y literatura españolas en la obra de José Martí, Eds. de la Universidad de Salamanca, 1995; José Joaquín Fernández de Li zardi, El Periquillo Sarniento, Edición crítica, Madrid, Cátedra, 1997; Álvaro Mutis, Summa de Maqroll el Gaviero. Poesía, 1948-1997, Ediciones de la Universidad de Salamanca, 1997; Rubén Darío, Antología, Madrid, Espasa Calpe, 1999, $3^{\text {a }}$ ed.; José Balza, Percu sión, prólogo de C.R.B., Caracas, Fundación Biblioteca Ayacucho, Colección Futuro, 2000; José Balza, Un Orinoco fantasma, prólogo de C.R.B, Salamanca, Centro de Estudios Ibéricos y Americanos, 2000; Rubén Dario, Colección Autores Literatura Universal, Madrid, Ed. Síntesis, 2002.

Alejandro Querejeta, «La felicidad está pasada de moda», [entrevista al autor] en WV. AA. EI exilio interminable. Vásconez ante la crítica, Quito, Paradiso Eds., 2002, pág. 28.

Javier Vásconez, Ciudad lejana Edición definitiva, Quito, Alfaguara, 2002. Citamos las páginas por esta edición entre paréntesis en el texto.

3

Alejandro Querejeta, «La felicidad está pasada de moda», [entrevista al autor] en WV. AA. El exilio interminable. Vásconez ante la crítica, op. cit., págs. 21 22.

Marqueses en la colonia, la evocación del antiguo régimen en Ciudad Lejana de Javier Vásconez CARMEN RUIZ BARRIONUEVO

\title{
MARQUESES EN LA COLONIA, LA EVOCACIÓN DEL ANTIGUO RÉGIMEN EN CIUDAD LEJANA DE JAVIER VÁSCONEZ
}

\author{
CARMEN RUIZ BARRIONUEVO
}

Inventar una ciudad fue, desde el comienzo, el centro de la narrativa del ecuatoriano Javier Vásconez (1946), uno de los valores más sólidos del panorama literario de su país por el rigor de su escritura y por la conciencia, presente siempre desde sus primeros relatos, de que el escritor debe poseer un universo único e intransferible, un espacio que debe urbanizar con criaturas de su propia invención, que a la vez respondan a un plan preconcebido de antemano y tras cuyos destinos se nos convoca a una personal visión del mundo. Obstinado en crear espacios autónomos, en la línea de William Faulkner, al que considera el narrador más influyente en la narrativa hispanoamericana, ( «Hay que admitirlo. En América Latina todos somos descendientes de Faulkner $\left.{ }^{1}\right)$, necesita explorar y habitar esos espacios, que una vez poblados, las criaturas traspasan de improviso hacia otros habitáculos que la escritura va creando. Vásconez es autor de una reducida pero cohesionada obra, dos novelas: El viajero de Praga (1996) y La sombra del apostador (1999) y otras colecciones de cuentos como El hombre de la mirada oblicua (1989) y Café Concert (1994), relatos que selecciona junto con la novela corta $E l$ secreto (1996) en un volumen de 1998, Un extraño en el puerto.

Pero la narrativa de Vásconez comienza, en realidad, con la compilación de los once relatos que reúne en 1982 con el nombre de Ciudad lejana, y que vuelve a publicar en ver- sión definitiva en $2002^{2}$. Son cuentos que establecen un punto de convergencia y de recurrencia en su obra y que responden a un mismo escenario, el del pasado de la capital de Ecuador, Quito, pero no desde el punto de vista descriptivo e histórico, sino desde una perspectiva ficcional en la que domina la visión de una antigua ciudad aislada, poblada por habitantes que son víctimas del delirio o de la ilusión en un marco de decadencia de los antiguos ideales. Confía en una entrevista:

Ecuador siempre aparece en mi obra. Pero he intentado interiorizar y describir desde otros ángulos a la gente de ese país. No me interesa la ciudad como historia. Ni como retrato de costumbres, sino como escenario de unos cuantos personajes. Me interesa inventar la naturaleza de esta ciudad. Evocar su vibración, su atmósfera, la luz que irradia -esto es para mí muy importante- y, por último, captar su densidad sicológica. De hecho Quito ha pretendido olvidarse de sí misma, dar la espalda a su pasado barroco y español, rechazando de algún modo su modesta tradición europea ${ }^{3}$.

Mercedes Mafla, en uno de los mejores estudios sobre su obra, complementa esta opinión del autor al señalar que, a diferencia de otros narradores coetáneos, Vásconez irrumpe en la literatura ecuatoriana recreando «el desmoronamiento de los grupos antaño poderosos frente a la inminencia de una tardía modernidad» y, citando a Eliécer Cárdenas en 
una reseña de su primera colección de cuentos, justifica que «la decadencia, el eclipsamiento de los viejos valores señoriales» es el tema más apreciado por los narradores de momento porque tal vez responda a una «una necesidad nacional», a la urgencia por «abolir el pasado, sepultarlo con un epitafio literario que rezuma rabia pero también nostalgia» ${ }^{4}$. Esa nueva veta, que se afianza en la narrativa ecuatoriana por esas fechas, adopta en los relatos de Vásconez el tiempo ritualizado de la Colonia proyectada a través del siglo XIX hasta el XX, a través de anónimos personajes pero también de la sugerencia de emblemáticos nombres, para explorar, a través de ellos el pasado de la ciudad. Se puede decir que esos relatos incorporan por sus intersticios esa historia, pero no buscan de modo directo los hechos relevantes, sino que se limitan a la sugerencia de un determinado ambiente, casi siempre a través de personajes laterales o intrahistóricos, porque propician una mirada de ese lejano motivo desde sus márgenes. Y todo ello entendido desde una perspectiva que podemos emparentar con la condición posmoderna que una estudiosa de la novela histórica, como María Cristina Pons, señalaba para la nueva narrativa histórica latinoamericana, en la que se «niega el proyecto de emancipación propuesto por la modernidad $»^{5}$ en tanto en cuanto ésta no ha resultado una propuesta convincente para el presente de esas naciones. En esa línea, los relatos de Vásconez ambicionan un universo constituido por un espacio generador y desgarrado en el que la violencia, la soledad, las pasiones, el desencanto y la frustración son las notas más decisivas: «He asistido a la ruina del Quito antiguo, a lo que hoy día llamamos la ciudad vieja, que era una forma de vivir y de ver las cosas. Ahora todo aquello es una ciudad lejana, fuera de tiempo, un retablo barroco o un lugar anclado en la historia» ${ }^{6}$, confiesa. Y más adelante insiste en esta perspectiva de su narrativa desde mismo vértice que establecen los relatos de Ciudad lejana:

Es un recorrido por el centro de la ciudad y por su pasado - barroco y lleno de iglesias- en donde transcurrió mi infancia tratando de hacer saltar con un alfiler los ojos de vidrio de los santos o levantando la falda de las vírgenes, y terminaba decepcionado al encontrarme con unos muslos apolillados. Algunos de esos cuentos son retablos barrocos. Rinden tributo a ciertos barrios de esta ciudad. Es un compendio sobre la arquitectura del Quito antiguo con sus fachadas, su manierismo y la decoración interior de las casas coloniales. Es un libro sobre los horrores y terrores de mi infancia?.

En efecto, el lector encuentra en esta colección un intento fundacional de espacios y de personajes muy visible en la mayor parte de los títulos, intento realizado sobre todo en torno a una serie de recurrencias que encajan en el ambiente de la ciudad, pero también de una familia, la familia Castañeda. Tres tipos de personajes encarnan y propician la mirada intrahistórica de ese espacio histórico: la mujer anciana o viuda, abandonada o decrépita que convive con su criados; la voz adulta que recrea los recuerdos de su infancia elitista y su convivencia jerarquizada con los criados; y los personajes marginales que desde su especial postura se yerguen como acusadores de un orden dominante. En todos esos relatos el juego temporal de pasado presente se nos concita como una sugerente e incisiva dualidad de contrastes.

No es casual, por eso, que el relato «Historia secreta de una campanilla» esté colocado al inicio del libro, pues su intencionado sesgo se proyecta en los textos sucesivos. Ese toque de campanilla, leitmotiv simbólico de la autoridad perdida, llama la atención respecto a un pasado, y alcanza un significado fetichista, enunciador en su repique, de un tiempo que fue y que ya no es, el tiempo dorado de los próceres, marcado por la «ardiente evocación del General que alguna vez penetró en la Plaza de la ciudad montando un garañón de paso corto» (14), con el que se inició una época de pujos aristocráticos, apariencias y lujo, de la que tan sólo queda el eco de esa campanilla, que antaño «significó la gloria familiar» (21), y que ahora repica inútilmente la patrona. La duplicidad temporal del monólogo, pues el presente de decrepitud de la anciana convoca el tiempo pasado de la historia, emerge con el recuerdo de la figura del General Juan José Flores, ese bisabuelo evocado, en su añorado don de mando pero también en su visible realidad de tosco oportunista con que se inserta en el tiempo: «recuerda la patrona que su bisabuelo fue un mulato sin pasado, triunfa-
4

Mercedes Mafla, «El exilio interminable» en VV. AA. El exilio interminable. Vásconez ante la crítica, ibidem, pág. 46.

\section{5}

María Cristina Pons, Memorias del olvido. Del Paso, García Márquez, Saer y la novela histórica de fines del siglo $X X$. México, Siglo XXI, 1996: «no podemos desconocer que el pensamiento posmoderno, en tanto manifestación de ese cambio de las condiciones de producción material y simbólica, afecta a la novela histórica de manera particular. Y la afecta no sólo porque una de esas grandes narrativas cuestionadas por el pensamiento posmoderno es la Historia misma, sino también porque la novela histórica ha venido cumpliendo a lo largo de su trayectoria una función de afirmación de los valores de la modernidad» (pág. 23).

6

Alejandro Querejeta, «La felicidad está pasada de moda», [entrevista al autor] en VV. AA. El exilio interminable. Vásconez ante la crítica, op. cit., pág. 23.

7

Ibidem, págs. 24-25.

Marqueses en la colonia, la evocación del antiguo régimen en Ciudad Lejana de Javier Vásconez CARMEN RUIZ BARRIONUEVO 


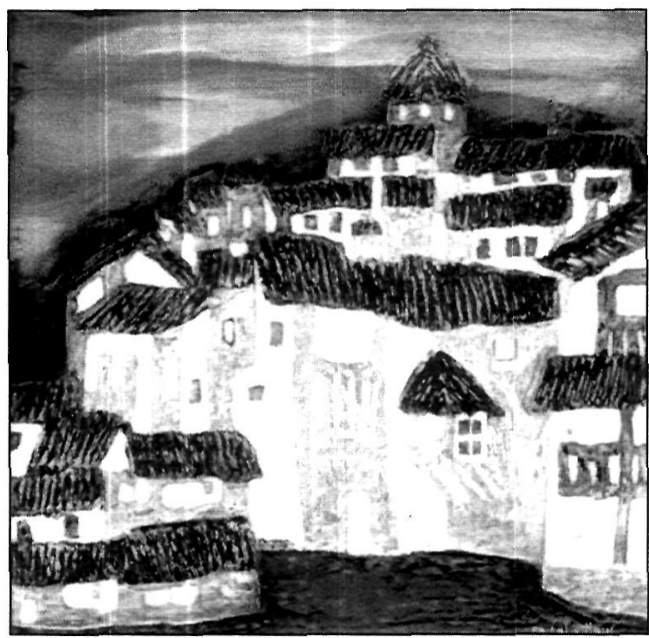

8

Javier Ponce: «Javier Vásconez, atado a una máquina de escribir», Ibidem, pág. 12.
Marqueses en la colonia, la evocación del antiguo régimen en Ciudad Lejana de Javier Vásconez CARMEN RUIZ BARRIONUEVO dor general republicano, un canalla con talento que se supo aprovechar del ajedrez, o sea de la historia» (14). La historia oficial nos dice que el General venezolano, Juan José Flores, en una mañana de mayo de 1830, mediante una asamblea de vecinos y notables, declaró que la antigua Presidencia de Quito se separaba de la República de Colombia y se constituía en estado independiente, dando así el primer paso para la constitución de la República del Ecuador de la que fue presidente durante dos periodos entre los años 1831 y 1845. Ambicioso, soberbio, pero con notable carisma, ese mesiánico general marcará en la memoria de la anciana el comienzo de una época que, a través de la escritura Vásconez, se presenta con esperpéntica sugerencia. No en vano la patrona es heredera del mismo linaje que en ese presente concluye para siempre. Los dos epígrafes, al comienzo del texto, inciden además en esta lectura, -uno de Shakespeare, «Atrás, estercolero, ¿osas desafiar a un noble, tú?», y otro, una cita bíblica del Libro de Ezequiel, que reproduce los mandatos de Yahveh al profeta, «Y comerás pan de cebada y lo cocerás con los excrementos que salen del hombre y a la vista de ellos» (IV,12)- ambos bien expresivos el primero de la marcada jerarquía social, y el segundo, de la mísera condición humana que se hace muy evidente en la vejez de la patrona. Con todo ello, y con este relato inicial, se marca de manera clara esa intención que traslucían las palabras de su amigo Javier Ponce cuando se refería a los comienzos del autor ecuatoriano: «Los pecados y los hábitos secretos y bárbaros de una aristocracia andina, comenzaban desde entonces a habitar su literatura» ${ }^{8}$. Pero para cumplir ese objetivo era necesaria esa dualidad temporal en la construcción del relato, pues de ese modo se engarza la mirada irónica y deformadora; construcción instaurada tan sólo por la única voz narrativa de la patrona que se corresponde además con otra dualidad en el funcionamiento de los personajes, es decir de la relación jerárquica de ama y criada, invertida por necesidad, pues la patrona exhibe una total su- bordinación física a ésta. Así, atraída al presente, se nos delimita no sólo la diferencia de clases, sino la pugna que existe entre ellas: Frente a la libertad de Brígida, la patrona ha dejado transcurrir la mitad de su vida en la clausura del dormitorio (16), viviendo de recuerdos, abandonada al alcohol, pues «Antes del mediodía ya estará borracha, esperando la llegada de la Brígida» (19), proyectándose en un presente de decadencia extrema que refuerza el espacio de la casa, desprovista de muebles, oculta por gruesos cortinajes, que la aíslan en su soledad y en su grotesca dependencia, para realizar cualquier acto físico, del cuidado de la criada. "¿Dónde estará la Brígi$\mathrm{da}$ ?, piensa la patrona tocando esa misma campanilla que hoy día es su única comunicación con el mundo, con la ciudad extraña y lejana que se extiende ahí afuera» (15), una ciudad, un tiempo, una historia sobre la que se insiste en proyectar la inútil autoridad del toque de la campanilla y que, casi al final de su monólogo, la patrona acepta que ha concluido «como un viejo álbum de familia» (22). Por eso la última imagen del relato presenta la angustia, ya terminal, de esa anciana inmóvil en la cama, alcanzando a ver la partida alegre de la sirvienta, y cómo Brígida, «cargando su atado de ropa, se marcha danzando al son de una campana. De una campana que no es la suya, mientras en la calle un esplendoroso cielo azul parece inundarlo todo» (24), gesto que marcaría de forma emblemática el comienzo de la nueva época, el fin de la sometida servidumbre y el acabamiento del antiguo régimen.

Es este un relato que introduce, como vemos, a dos de los personajes recurrentes de la obra de Vásconez y con los que comienza a erigir su mundo propio, el de la mujer de la aristocracia, sea patrona o marquesa, y el famoso General, el prócer de un tiempo pasado, así como incorpora los dos tiempos: la utópica edad lejana de la ciudad, proyectada en un presente de decadencia no exento de irónica circularidad. Pero si este cuento funciona como marco e inicio que emblematiza el contenido del libro, los relatos que se suceden a continuación ejercen el carácter de retablo de ese tiempo inestable, en su juego temporal de pasado y presente, con la concurrencia de otros personajes que va trabando la enunciación del eminente apellido Castañeda, recurrente saga de prelados, nobles y damas aristocráticas que, en la ciudad creada por 
Vásconez, se resisten al cambio o que contemplan incrédulos la disolvente aparición de la nueva época.

Prueba de que el autor encontró un elemento estético de importancia en estas dualidades, lo ofrece el que aproveche el mismo paradigma del relato de apertura en otros que aparecen a continuación, como es el caso de «La marquesa» y «Mamía linda». En ellos el centro vuelve a ser la mujer de la aristocracia, que se niega a aceptar el presente y es víctima del cambio de costumbres de los tiempos, con lo que se sume en la soledad y en el abandono, siempre ante la amenazadora presencia de la muerte. En «La marquesa», -situado en la compilación inmediatamente después de «Historia secreta de una campanilla»-hay escasa diferencia en la presentación de los personajes, aunque en este caso el barroquismo del decorado y la abundancia de la vegetación tropical propicia una variante de la misma decadencia. En todo caso el personaje sufre un proceso de desposesión, marcado en el comienzo, hasta hacerse evidente su desnudez:

Desprovista del corpiño que la incomodaba tanto, la marquesa fue quitándose con una suerte de lánguido impudor las otras prendas de vestir: una enagua de organdí vaporoso, una cinta de color carmesí que sujetaba su larga cabellera, un calzonario de seda rosa, un par de borceguíes rematados en lazón de raso, un camafeo de oro viejo que colgaba entre sus senos... Desnuda en medio de la penumbra, los espejos se negaban a reproducir su silueta recortada como un helecho (27).

El relato que nos ocupa tiene un referente histórico, pero a Vásconez no le interesa la descripción explícita, porque no busca individualizar los motivos sino convertir a sus personajes en grandes símbolos universales de la soledad, la decadencia y el abandono del ser humano. De este modo, y a través de las fantasmagóricas apariciones dibujadas en el anochecer del jardín abandonado, puede entreverse la vida de otro personaje ilustre de la historia ecuatoriana, la de doña Mariana Carcelén y Larrea, Marquesa de Solanda", viuda del General cumanés Antonio José de Sucre, con la que contrajo matrimonio en abril de 1828 y con la que convivió apenas dos años, pues fue asesinado en Berruecos en 1830 , lugar al que hará referencia el texto en su parte final, y dato que propicia que el lector avisado pueda, -cosa que no es estricta- mente necesaria- identificar a la innominada marquesa.

Vásconez vuelve a marcar en este relato la misma intencionada dualidad de marquesa y criada que en los relatos anteriores, esta última ausente, lo que refuerza la sensación de soledad: "Pero era inútil que deseara compartir su angustia y su soledad con alguien, porque $\mathrm{Ma}$ ría descansaba plácidamente en el pueblo» (28). Es éste sin duda un relato más evocador que el precedente en el plano de los recuerdos personales, al poner en pie a figuras de antaño que reviven en el presente su impotencia ante el trascurso del tiempo, como cuando ese sujeto femenino evoca la música del piano, viejo e inservible, pero que propicia la reviviscencia de su primer amor: «Revivió una noche en casa de los Castañeda, cuando las notas del piano se habían prolongado en frufrúes de seda hasta el amanecer» (28), gesto con el cual integra a la Marquesa en el círculo aristocrático de la emblemática familia de la narrativa del escritor ecuatoriano. A ello se une que otras imágenes, igualmente fantasmagóricas nos devuelven sus emociones, como cuando al descender a su abandonado jardín, presa de un confuso vendaval, el espejo le reproduce su imagen solitaria: «Contempló la marquesa su propia figura disminuida en los cristales de la ventana, casi oculta tras los flecos de la manta» (29), acompañada con un extraño y confuso galope de caballos. Piano y galope, fundidos en la música, son indicios de un presentimiento de muerte bien marcado por el desenlace del cuento, real y fantástico a la vez, pero en todo caso expresivo de su inminente situación de viuda: «la marquesa supo que habían asesinado al general en Berruecos y entonces se sintió Santa Lucía, y cubriéndose los senos con la mano se convirtió en una serpiente enroscada en las patas de una bestia enfurecida que el jinete ya no podía sujetar» (32). Al fin y al cabo también la Marquesa puede ser un paradigma universal de cuanta mujer joven y hermosa, es arrancada de su marido por una guerra incomprensible.

En esa resistencia al paso del tiempo que estas mujeres aristocráticas simbolizan, es el cuento «Mamía linda» aún más significativo. Esa Niña Mercedes, a la que visitaba su prometido Rosendo Sánchez con casaca azul y sable al cinto, quería vivir en el pasado: «Rechazó el paso del tiempo. Rechazó las campanadas de relojes, cuyas manecillas ahora repo-
Véase Cristóbal de Gangotena y Jijón, "Los amores de Sucre» en Edgar Freire Rubio: Quito, tradiciones, testimonio y nostalgia, tomo 2, Quito, Dirección de Educación y Cultura, 1991, págs. 115-121.
Marqueses en la colonia, la evocación del antiguo régimen en Ciudad Lejana de Javier Vásconez CARMEN RUIZ BARRIONUEVO 
san en silencio, a la hora de la siesta. Así la ciudad perdió, definitivamente, el sentido del tiempo» (83). Convertida en Mamía linda, atrapada como en una fotografía durante más de medio siglo, espera en la noche, varicosa e impedida, que la sirvienta anuncie a sus visitantes amorosos desde la primera y aciaga confusión con Rosendo, porque «jamás ocultó el secreto placer de recibir cada noche a un nuevo caballero en su lecho de encajes» (84). Si en este presente no se reconoce a la muchacha que recibía vestidos de París porque ahora se consume en degradante y agónica putrefacción en la soledad de su lecho (87), -de nuevo Vásconez emplea idéntico juego temporal- al mismo tiempo la casa colonial, sus puertas y mobiliario, junto con su sufriente imaginería, se desmoronan, y así lo ejemplifica ese «inmenso Cristo, erecto como un tirano inquisidor sobre peana de oro y plata en los sombríos recovecos del salón» (85). Un cuento éste cuya mirada percibimos potenciada por el humor, sobre todo en las páginas finales, en las que, en medio del desmoronamiento físico, que en su hipérbole grotesca recuerda a la Mamá Grande garciamarquina, los encuentros amorosos con don José se convierten en sesiones sadomasoquistas: «De vez en cuando cruzaba la calle para transformar el cuerpo de Mamía linda en un campo de moretones» (87) y en la divertida confusión de identidades que cierra el cuento.

Son pues, estos tres títulos, variantes de la misma imagen, ancianas agónicas o mujeres que rompen con pasados de esplendor, todas ellas entroncadas con un mismo ambiente ciudadano en el que domina el palacete de los Castañeda. Es evidente que la cita de este edificio en el relato "Mamía linda» como el lugar que alberga los últimos momentos de la protagonista propicia su ubicación en el espacio y su identificación como perteneciente a la misma saga aristocrática. Lo mismo sucede en otros cuentos que hacen referencia a la misma familia por medio del ejercicio de recuperación de la memoria, incluso tras una mirada infantil, en los titulados «El caballero de San Juan», «Recuerdos en el fondo de un espejo» $\mathrm{y}$ "La sangre», que remiten todos a indagaciones en el pasado familiar. En el primero la voz narrativa, que se retrotrae a la infancia, se presenta en el pasado como «un Julio César de cartoncillo y tambor de hojalata, iniciando el ascenso de las escaleras con aprobación de mamá, como si fueran los Pirineos» (39), al recorrer los salones y galerías de la vieja casa heredada, cuyos muros sostienen la imponente «presencia inconfundible del Obispo Castañeda» al lado de otros «retratos familiares [que] soportaban la fiereza de mis ataques» (35). La presencia del Obispo Castañeda, cuya fama prolonga la madre (41), aparece por un lado como ese «Prelado noble e ilustre en la época colonial, [que] ahora me juzgaba desde su retrato con ojillos de rata» (40), pero por otro, el ilustre apellido se presta a introducir irónicas alusiones acerca de una familia que se resiste al cambio y prolonga contradictoriamente su grandeza: «Aprendí entonces que se puede ser romano, es decir poderoso, si detrás hay plata y obispos ilustres» (36), o en su infantil megalomanía, reforzando la idea: «Me tranquilizaba pensando que yo era rey» (42). De nuevo encontramos las dos clases sociales jerarquizadas, representadas aquí por el niño de nueve años de la familia aristocrática y por el negro Ramón, que le advierte: «cuidado niño, cuidado que los otros lo van a golpear» (37), así como por la resistencia de la criada Petamaría que «nunca admitió, por lo demás que pasara la infancia degollando azaleas y perritos como si fuesen galos» (37). El conflicto social queda en este relato expresado a través de parecido paradigma que en los precedentes, pues frente al mundo de los criados existe el de los amos: el niño epiléptico, caprichoso y violento, la madre consentidora y débil de pujos aristocráticos, que con humor se describe en el cuento:

Pobre mamá, siempre sujeta a su pasado de conventos, obrajes y alcabalas me cambió la vida proporcionándome aquel disfraz de Julio César, afirmando además que la familia Castañeda estaba a la par de Margarita de Navarra y César, cayéndose de su jamelgo en plena batalla de Farsalia» (41).

Aún más, el traje de romano con el que el niño va a la escuela después de su ataque epiléptico lo inviste, irónicamente, como superior en su clase social: «Al fin y al cabo, yo era superior a todos ellos ya que padecía síncopes de familia ilustre. ¿Quién era, por ejemplo, el pecoso Murieta?» (41). Pero si este cuento evidencia sobre todo esa dualidad social en cuanto tiene de antecedente en la colonia, en cambio «Recuerdos en el fondo de un espejo» introduce el pasado en el presente, pues una 
voz, que confiesa su rechazo (¿Por qué volví a esta ciudad con sabor a muerte? 97) pero también su nostalgia, retorna a recuperar su infancia y encuentra la ausencia de cualquier cambio dentro de una casa en la que, «los ilustres retratos de familia todavía acechan a mi alrededor con rostro grave, desdeñoso, terrible, ejerciendo un curioso magnetismo sobre mí» (95). La casa colonial, con su lujo desvaído y su inevitable ruina, "caverna infame, inhóspita, donde los ratones anidan con absoluta libertad en los armarios, tras los cortinajes, bajo el tocador de tía Esther» (96) encierra, en este caso, a personajes como el aristocrático y conservador tío Reynaldo que, en su locura actual, ("Odio esta raza de enanos que habitan la ciudad, odio a los hombres porque no significan nada para mí...» 97), hace revivir un pasado imposible: el enfrentamiento y la venganza contra otro personaje histórico, el general liberal Eloy Alfaro. Dentro de la historia ecuatoriana este general, amigo y seguidor de Juan Montalvo, tras la revolución de 1895, ejerció como presidente del Ecuador en dos periodos sucesivos (1896-1901; 1906-1911) y trató de realizar reformas progresistas, muy criticadas en su país, como la reducción del poder de la Iglesia, la libertad de cultos, el matrimonio civil, el divorcio y la nacionalización de los bienes eclesiásticos. En el fondo, este cuento como el titulado "La sangre», hacen referencia a los dolorosos recuerdos de las guerras civiles que jalonan esos años, de ahí las premoniciones, los presentimientos de malos augurios que siembran el apocalipsis en la ciudad ( Dice que entonces vio la iglesia hundirse en la tierra fatal de sus antepasados» 125) para ofrecer el significado más auténtico del enfrentamiento: «Dice que el abuelo disparó porque no podía admitir invasores en su tierra, menos aún si estos eran liberales» (127). De este modo, en estos tres cuentos, con levísimos pero acertados rasgos históricos, se hace alusión al ámbito ecuatoriano, pero sin interferir en la interpretación más universal y arquetípica.

Varios cuentos dentro de la colección presentan personajes marginales o insólitos, que completan el recinto de la ciudad lejana en la obra del escritor ecuatoriano, como «Sor Juana Rosa», cuyo entorno colonial emana de la ambigua milagrería inquisitorial en la que se combina superstición religiosa y erotismo, pues al recibir a la «Santa de las flores»
(56), «la mirada voluntariamente cruel, inquisidora, del canónigo sucumbió ante la belleza melancólica de Sor Juana Rosa» (57) que acto seguido se abandona a una histriónica felación que le practica la Santa con sus «labios sensuales y carnosos» (60), mientras musita: «Sor Juana llegarás al reino de las flores» (61). O «Cristo Rey», donde el bandido desafiante, Bautista Semblantes, apodado Cristo Rey, es conducido a la horca ante la mirada de la ciudad, aun cuando la muchedumbre lo aclama con pasión, pues es acusado de diversos delitos, entre ellos de escupir al cuerpo del Señor y de haber robado a la Iglesia y a la ilustre familia Castañeda. El texto, lleno de duplicidades y de ironías, presenta el desafío del orden social y actualiza el conflicto irónico y jocoso entre pueblo y aristocracia, presente en similares historias de ejecuciones reales de la Colonia. Ambos pueden ser arquetípicos de esa época virreinal, pues como señala Mercedes Mafla:

Estamos en el momento en el que las colonias españolas vivían una auténtica secularización de la mística, una especie de estetización de la vida cotidiana. Vivir en un teatro permanente (el theatrum mundi) era la regla, de ahí que tanto Juana Rosa como Doña Celestina o Bautista Semblantes (autoproclamado Cristo Rey) lleven nombres motivados, nombres que nos remiten a una duplicación evidente ${ }^{10}$.

Pero sin duda, si queremos buscar un personaje productivo para la construcción de la ciudad de Vásconez es el de Roldán. Presentado en el cuento titulado «Roldán, el misterioso» por el capitán Romero como «Roldán, el misterioso: un hombre maltrecho y medio paralítico» (102) y también como «el astuto soplón con quien frecuentaba ciertos sitios, lo guiaba por la ciudad, conseguía información de primera mano y nunca pagaba a las putas» (102), Roldán remite, por un lado, al pasado de decadencia pero también al presente abyecto de la ciudad. En él decadencia y marginalidad han llegado a su coincidencia pues, procedente de la renombrada familia Castañeda, ha llegado a ser el «rey indiscutible de la noche, las putas, los abismos de la luna y la ciudad» (109). Es así como Roldán representa el corazón mismo del recinto urbano, sus insólitos y degradantes sucesos, en medio de los cuales no puede evitar padecer una enfermiza soledad, pero al mismo tiempo los fantasmas
10

Mercedes Mafla, «El exilio interminable» en V. AA., El exilio interminable. Vásconez ante la critica, ibidem., pág. 56.
Marqueses en la colonia, la evocación del antiguo régimen en Ciudad Lejana de Javier Vásconez CARMEN RUIZ BARRIONUEVO 
Javier Vásconez, El hombre de la mirada oblicua, Quito, Eds. Libri Mundi, 1989.

\section{2}

Javier Vásconez, La sombra del apostador, México, Alfaguara, 1999. de sus sueños evocan a antepasados ya conocidos y temidos, como el perfil aguileño de su abuelo, los retratos de la casa colonial, las porcelanas y los gobelinos del salón. Ello fortalece su memoria, temerosa y acomplejada, frente a ese abuelo amenazante, el coronel Juan Manuel Castañeda, que cobra vida entre las sombras del pasado: «otra vez el Coronel acuñado como una moneda en su memoria» (105). Un abuelo al que todos temían porque se había impuesto como invencible conquistador en la Región del Valle, con sus arrogantes galopadas en las que demuestra la superioridad de los caballos frente a todo ser humano, y desde luego del propio Roldán, minusválido desde niño. $\mathrm{Y}$ ser deforme en una casta aristocrática implica también una necesidad de buscarse a sí mismo. Es así como este personaje, inútil para el esfuerzo físico, y rechazado por la opinión del abuelo, llegará a odiar a los caballos y cuanto ellos significan de poder y alcurnia social, y en consecuencia a la vida misma en la que se siente perdedor. La ciudad a la que llega ( Una ciudad sin horizonte: una ciudad colgante como los altares de sus iglesias» 115), es así el único asidero para un hombre, que cargado con un maletín de plástico y sus torpes muletas, se interna en todos los estratos de la sociedad, y en cuya trayectoria, que exige el exacto dominio de sus sentimientos, un tú que duplica su interioridad le convence de apostar por el futuro: «compensarás esa impresión adueñándote de la ciudad y sus enigmas. Y tú pensarás, Roldán -rey indiscutible de la ciudad, los naipes y el billar- pen- sarás que después de todo eres el misterioso Roldán» (114).

Esta figura de Roldán, que se trasvasa a otros textos del ecuatoriano como «Un resplandor en la ventana», -incluido en la colección El hombre de la mirada oblicua ${ }^{11}$ y que remite a su primera visita a la ciudad, frente a la cual sopesa su horizonte de perspectivas- o a «Crónica de la sangre», -en la que, con la excusa de indagar la causa del asesinato por él cometido, se entrelaza una amplia crónica familiar de la aristocrática familia Castañeda- se convierte en punto de fundamental enlace para ir tejiendo el ambiente total de esa ciudad que en definitiva persigue la narrativa total de Vásconez. Por eso la figura de Roldán va siendo diseñada y retomada en momentos varios de su vida en otros textos, aunque es en su última novela, La sombra de apostador ${ }^{12}$, donde se recuerda su pasado, se reproducen anécdotas vividas y se nos muestran sus rasgos con mayor dimensión, con el objetivo de completar y acentuar la dimensión de su maligno carácter.

Si bien la obra de Vásconez se desliga en la actualidad de las anécdotas estrictas de su primer libro, con sus alusiones históricas, Ciudad lejana sigue siendo el semillero de su articulación espacial de la ciudad, y múltiples lazos ambientales, así como varios personajes, como Roldán, saltan a otros relatos y a otros libros, trazando un tipo de obra que, si bien no puede incluirse con propiedad en la nueva novela histórica, en cambio nos remite a un contexto nacional ecuatoriano. 